\title{
PESQUISA APLICADA COMO INOVAÇÃO METODOLÓGICA NO JORNALISMO: dimensões teórica, empírica e experimental
}

APPLIED RESEARCH AS METHODOLOGICAL INNOVATION IN JOURNALISM: theoretical, empirical and experimental dimensions

INVESTIGACIÓN APLICADA COMO INNOVACIÓN METODOLÓGICA EN EL PERIODISMO: dimensiones teórica, empírica y experimental

\section{Tássia Becker Alexandre}

Jornalista. Doutora pelo Programa de Pós-graduação em Ciências da Comunicação da Universidade do Vale do Rio dos Sinos (Unisinos). Professora substituta do curso de Jornalismo na Universidade Federal de Mato Grosso (UFMT), campus Cuiabá. tassia.becker@gmail.com

\section{0-0003-2383-3358}

\section{Maria Clara Aquino}

Pesquisadora e docente do Programa de PósGraduação em Ciências da Comunicação da Universidade do Vale do Rio dos Sinos (Unisinos). Doutora e mestre em Comunicação e Informação pelo Programa de Pós-Graduação em Comunicação e Informação da Universidade Federal do Rio Grande do Sul (UFRGS).jaquino@unisinos.br

\section{0-0001-8230-5921}

Correspondência: Universidade do Vale do Rio dos Sinos, PROGRAMA DE PÓS-GRADUAÇÃO EM COMUNICAÇÃO, Av. Unisinos, 950. Bairro Cristo Rei, 93.022-750, São Leopoldo, RS - Brasil.

Recebido em: 16.02.2021.

Aceito em: 16.04.2021.

Publicado em: 01.07.2021.

\begin{abstract}
RESUMO:
Este trabalho objetiva debater a pesquisa aplicada como uma perspectiva de inovação metodológica no jornalismo por meio do relato do processo de construção de uma investigação de doutorado sobre jornalismo móvel. Para tanto, relacionamos inovação e crise no jornalismo e abordamos aspectos referentes à pesquisa aplicada no campo. Também destacamos os processos metodológicos desenvolvidos na tese, refletindo sobre a articulação do que denominamos como dimensões teórica, empírica e experimental da pesquisa aplicada. Ainda, abordamos a experimentação teórico-metodológica neste tipo de investigação, o papel da academia para a condução de pesquisas aplicadas e as limitações e potencialidades desta perspectiva de pesquisa para o jornalismo
\end{abstract}

PALAVRAS-CHAVES: Pesquisa aplicada; Processos metodológicos; Jornalismo móvel; Inovação.

\section{Introdução}

As questões envolvendo jornalismo e dispositivos móveis têm sido tema de reflexão na academia, que observa a problemática de diferentes perspectivas, como a partir das transformações na prática jornalística, mudanças nos formatos, narrativas e interfaces, novos produtos e ferramentas, e análises sobre consumo de informações e interação entre usuários e veículos via dispositivos móveis.

Com base em uma revisão de periódicos científicos, López-García et al. (2019) destacam a ampla produção relativa ao jornalismo móvel dos últimos anos. Segundo os autores, predominam as publicações com caráter descritivo, de recorte tecnológico, especialmente relacionadas à influência da inovação na produção jornalística. No entanto, realçam que o campo ainda apresenta lacunas de investigação, sendo escassos 
os estudos analíticos e práticos referentes à emissão, difusão e recepção de conteúdos móveis.

No que tange aos estudos práticos, uma das perspectivas que se aproxima desta linha investigativa é a pesquisa aplicada, a qual objetiva originar conhecimentos para aplicação na solução de problemas específicos, bem como usar os saberes já existentes para resolver não apenas o problema que motivou a investigação, mas também ampliar o conhecimento e gerar novos questionamentos sobre o tema (Prodanov \& Freitas, 2013). No jornalismo, Guerra (2016) entende que a pesquisa aplicada possui relação intrínseca com a prática, buscando, a partir da pesquisa científica, encontrar soluções de natureza teórico-prática para limitações ou insuficiências identificadas em um modo de fazer.

Neste contexto, este trabalho tem como objetivo debater a pesquisa aplicada como uma perspectiva de inovação metodológica no jornalismo por meio do relato do processo de construção de uma investigação de doutorado. A tese em questão teve como objetivo propor parâmetros para uma linguagem autóctone ${ }^{1}$ para smartphones e tablets a partir de uma pesquisa aplicada.

Inicialmente, realizamos uma breve abordagem sobre a crise no jornalismo e a importância em se pensar o novo nesse cenário. Na sequência, abordamos a pesquisa aplicada no campo jornalístico, conceituando-a e compreendendo-a como uma maneira de se inovar metodologicamente (Franciscato, 2017). Em seguida, detalhamos questões relacionadas ao desenvolvimento metodológico da tese sobre jornalismo móvel elaborada por uma das autoras sob orientação da outra. Por fim, apresentamos as considerações deste estudo.

Acreditamos que o relato da experiência de uma pesquisa de doutorado aplicada permite ampliar o debate sobre esse tipo de investigação, bem como refletir sobre possibilidades e desafios para essas pesquisas em programas de pós-graduação stricto sensu. Ainda, entendemos que a abordagem do processo de construção da tese pode ser relevante para outros pesquisadores que pretendem desenvolver estudos a partir dessa perspectiva metodológica.

\section{Crise e inovação no jornalismo}

As transformações sociais e tecnológicas, especialmente nas duas últimas décadas, tiveram efeitos em diversos âmbitos do ecossistema midiático e jornalístico. Carlón (2016) ressalta que os meios de comunicação vivem uma fase de intensas

\footnotetext{
${ }^{1} \mathrm{O}$ termo "autóctone" refere-se às produções originais para smartphones e tablets que utilizam conteúdos exclusivos e tratamento diferenciado (Barbosa et al., 2013).
} 
mudanças relacionadas à emergência de um novo sistema de midiatização e de novas práticas sociais. O autor esclarece que são desenhadas novas formas de exploração, autoexploração e dominação distintas daquelas instauradas pelos meios massivos, em que os sujeitos podem tornar seus discursos públicos através dos chamados novos meios, provocando a complexificação da circulação.

Observa-se, neste contexto, que a popularização da internet e o barateamento das tecnologias de comunicação garantiram a participação do público na produção e difusão de informações em maior escala e de forma mais rápida (Anderson, Bell \& Shirky, 2013). Ainda, práticas jornalísticas foram remodeladas e plataformas digitais e dispositivos, como smartphones e tablets, despontaram e contribuíram para alterações no modo como o conteúdo é produzido e consumido.

No que tange à prática, Silva (2015) aborda o uso de dispositivos móveis na produção, apuração e transmissão das notícias, destacando que a nova dinâmica caracterizada pelas tecnologias móveis e pelo processo de convergência possibilita ao jornalista estar mais próximo ao local onde os eventos ocorrem e realizar as coberturas com mais agilidade e facilidade - o que, em consequência, afeta a estrutura da redação, as rotinas produtivas e as estratégias de distribuição das informações.

Em relação ao consumo, estudos mostram que atualmente o acesso de notícias em smartphones é maior em comparação a outros suportes digitais, se dá especialmente por meio de plataformas de redes sociais e substitui ou complementa outros meios (Newman et al., 2020). O consumo é cada vez mais individualizado e os usuários também passaram a agir sobre o conteúdo (Aguado, Feijóo \& Martínez, 2015). Ainda, os hábitos de consumo de veículos tradicionais mudaram com as novas gerações (Thorson et al., 2015; Flamingo, 2019).

Outra transformação relativa ao contexto corresponde ao declínio das audiências, queda no faturamento e decadência do principal modelo de negócio das empresas jornalísticas tradicionais (o publicitário) (Newman et al., 2020; Pew Research Center, 2018). O jornalismo acabou por ver-se imerso em um contexto de impermanência na indústria, no ambiente de trabalho e nas carreiras (Deuze \& Witschge, 2016).

O panorama desafiador acaba por refletir-se no que Henn e Oliveira (2015) denominam como uma crise sistêmica, com efeitos na autonomia e na identidade do jornalismo. Anderson, Bell e Shirky $(2013$, p. 87) corroboram com os autores ao destacar que talvez a principal mudança do jornalismo pós-industrial ${ }^{2}$ esteja no enfraquecimento

2 O termo "jornalismo pós-industrial" foi criado em 2001 por Doc Searls para sugerir um jornalismo que não é organizado segundo regras do maquinário da produção (Anderson, Bell \& Shirky, 2013). 
do que constitui uma notícia e uma organização jornalística, com "menos clareza sobre aquilo que constitui o jornalismo propriamente dito".

A temática da crise não é, de fato, uma novidade para o campo jornalístico, que teve todo o seu desenvolvimento marcado por momentos de instabilidade e fases de transição (Charron \& Bonville, 2016). A crise atual é resultado de um conjunto de mudanças que vêm ocorrendo nas últimas décadas no jornalismo e nas práticas sociais, sendo necessário evitar determinismos e considerar a própria historicidade do campo. Do mesmo modo, é preciso realçar o caráter processual da mídia, percebendo-a como algo em constante transformação.

Em função disso, não se pode prever com exatidão qual será o futuro do jornalismo. No entanto, autores convergem na perspectiva de que flexibilidade e inovação são ideias centrais para a sobrevivência das instituições jornalísticas. Anderson, Bell e Shirky (2013), assim como Singer (2014), reconhecem os desafios provocados pelas recentes transformações no campo, mas realçam as oportunidades que se abrem ao jornalismo. Os pesquisadores são enfáticos ao afirmar que o único meio de sobreviver à crise é explorar novas possibilidades, experimentando formas de colaboração, usando ferramentas de análise de dados e criando outros modos de narrar os acontecimentos (Anderson, Bell \& Shirky, 2013).

No jornalismo, o entendimento sobre o que define uma inovação é centrado na novidade, sendo a inovação compreendida como o processo de criação ou modificação de práticas, produtos e serviços jornalísticos. Dentre os autores que investigam o tema está Cabrera González (2016), para quem uma inovação é a criação ou modificação de um produto ou serviço ofertado pelos meios de comunicação através da integração de novas tecnologias, rotinas e modelos de negócios em sua estrutura, organização, processos de produção e difusão de informações, com o objetivo de diversificar o mercado com alguma vantagem competitiva ou geração de valor.

Compreensão similar é apresentada por Storsul e Krumsvik (2013), que classificam cinco tipos de inovação no ecossistema midiático: inovação de produto ou serviço; inovação de processo; inovação de posição; inovação paradigmática; e inovação social. A partir dos autores, Dogruel (2017) desenvolve um paralelo entre quatro tipos de inovação descritos pelos autores (produto, processo, posição e paradigma) e quatro dimensões em que a mudança pode ocorrer (tecnológica, no design ou conteúdo, funcional e organizacional). Segundo a pesquisadora, a novidade pode enquadrar-se em mais de uma classificação e envolver mais de um tipo de mudança.

Outra pesquisa que distingue enfoques da inovação no jornalismo é a de Franciscato (2010, 2017), que elenca três dimensões: inovação tecnológica, que 
corresponde a procedimentos que envolvem a geração ou aplicação de tecnologias; inovação organizacional, referente às mudanças nas rotinas profissionais; e inovação social, relacionada aos usos ou efeitos sociais dos processos interativos e às interações entre sociedade e organizações jornalísticas.

A compreensão de inovação abordada até o momento tem como foco a prática profissional - os produtos, processos e modos de organização dos veículos jornalísticos. No entanto, inclui-se neste conjunto mais um nível do que se pode entender por inovação no jornalismo: a inovação na pesquisa. A próxima seção explora mais sobre esse aspecto, relacionando-o à pesquisa aplicada.

\section{Inovação nas investigações em jornalismo e pesquisa aplicada}

Além do mercado, a academia possui potencial para o desenvolvimento de projetos inovadores, pois é um ambiente favorável à experimentação e à transdisciplinaridade. Uma das formas de inovar no ambiente acadêmico é através da inovação metodológica, abordada por Franciscato (2017). Segundo o autor, este tipo de inovação alude ao campo conceitual, configurando-se como uma resposta a um problema científico, isto é, uma forma de buscar a compreensão de uma determinada realidade empírica quando há a inadequação de metodologias já existentes. Segundo Franciscato (2017, p. 37), "em um sentido amplo, a inovação é um processo contínuo, e a tarefa dos metodólogos da ciência talvez seja a de definir condições, estágios ou graus em que as mudanças consolidem novos modelos metodológicos de pesquisa".

A fim de debater a inovação metodológica no campo, Franciscato (2017) desenvolveu um estudo com artigos científicos relacionados ao jornalismo digital publicados entre 2009 e 2013. O pesquisador constatou que dois terços eram pesquisas empíricas e o restante configurava-se como investigação teórica ou ensaística. Nenhum trabalho era pesquisa aplicada, o que chamou a atenção do autor pelo fato de a metodologia ser "[...] útil para o desenvolvimento de processos e produtos jornalísticos em um ambiente constantemente reestruturado pelas tecnologias digitais" (Franciscato, 2017, p. 40).

Outros dois estudos que analisam anais de congressos acadêmicos brasileiros em comunicação e jornalismo corroboram com os achados de Franciscato (2017). Machado e Rohden (2016), que investigaram trabalhos apresentados no Encontro Nacional de Pesquisadores em Jornalismo (SBPJor) entre 2003 e 2007, verificaram a inexistência de pesquisas aplicadas no período examinado. Lopez e Maritan (2015), por sua vez, identificaram quatro publicações relacionadas à pesquisa aplicada em uma amostra com 
353 anais de eventos ${ }^{3}$, publicados de 2000 a 2014. No entanto, indicam que a produção foi concentrada em poucos autores, "[...] o que demonstra ainda uma reduzida aceitação desta perspectiva metodológica entre os pares" (Lopez \& Maritan, 2015, p. 13).

Mais especificamente sobre a comunicação e o jornalismo móvel, realizamos em junho de 2020 uma consulta ao Catálogo de Teses e Dissertações da Capes a fim de conhecer como os cursos de pós-graduação brasileiros da área estavam abordando a temática e quais trabalhos caracterizavam-se como pesquisas aplicadas. A busca foi desenvolvida a partir dos termos "comunicação móvel", "jornalismo móvel", "dispositivos móveis", "mobilidade", "ubiquidade", "smartphone", "tablet" e "smartwatch", tendo como recorte temporal o período de 2005-20194 e filtro de produções relacionadas a Ciências Sociais Aplicadas - áreas de Comunicação, Comunicação visual, e Jornalismo e editoração.

A pesquisa no portal permitiu identificar 292 dissertações e teses que contemplavam uma das expressões no título, resumo ou palavras-chave. Deste total, filtramos os trabalhos que estavam disponíveis para acesso on-line e que possuíam relação direta com dispositivos móveis $^{5}$, o que resultou em 188 pesquisas. Nesta amostra, sobressaíram as investigações empíricas, elaboradas a partir de diferentes métodos e técnicas de pesquisa, tais como levantamentos bibliográficos e documentais, estudos de caso, imersões etnográficas e pesquisas exploratórias. Dos 188 estudos, apenas sete $(3,7 \%)$ intitulavam-se como pesquisas aplicadas, sendo cinco relacionados ao jornalismo. Além destes, outros quatro indicaram resultados que visavam a solução de problemas práticos. Com esses resultados, foi possível compreender melhor o cenário nacional de investigações acerca da temática e ratificar o predomínio de pesquisas básicas na área (Alexandre, 2021).

O panorama evidenciado nos três estudos e no levantamento produzido para a tese não é, no entanto, uma novidade no campo. É, na verdade, resultado do contexto que envolve as pesquisas em comunicação e jornalismo há mais de um século. No princípio, as investigações na área foram marcadas pela experimentação, contudo, com o passar dos anos, a preocupação com a aplicação do conhecimento foi relegada, sendo desvalorizada frente a outras teorias e métodos (Renó, 2014).

\footnotetext{
${ }^{3}$ Congresso Brasileiro de Ciências da Comunicação (Intercom); Encontro Nacional da Associação Nacional dos Programas de Pós-Graduação em Comunicação (COMPÓS); Encontro Nacional de Pesquisadores em Jornalismo (SBPJor); e Encontro Nacional de História da Mídia (Alcar).

${ }^{4}$ Optamos por realizar a busca referente a 15 anos, acompanhando também a popularização dos dispositivos e a consolidação das práticas jornalísticas móveis.

${ }^{5}$ Foram desconsideradas as pesquisas que abordavam a mobilidade, ubiquidade e comunicação digital que não possuíam entre seus eixos principais os dispositivos móveis.
} 
Frente ao cenário atual, compreendemos que a pesquisa aplicada é um modo de explorar e propor ideias inovadoras no âmbito acadêmico. Retomando o conceito abordado na introdução deste estudo, a pesquisa aplicada objetiva produzir conhecimentos para a aplicação prática na solução de problemas específicos, possibilitando o emprego de diferentes métodos e técnicas de investigação (Prodanov \& Freitas, 2013).

No campo jornalístico, seguindo o entendimento de Guerra (2016), a pesquisa aplicada corresponde ao conjunto de conhecimentos sobre o jornalismo (próprios ou derivados de outras áreas), o qual sistematiza conceitos, fundamentos e relações para dar conta de um modo de fazer. "Dessa sistematização, extrai-se um problema de pesquisa, que é necessariamente um problema prático - uma limitação ou insuficiência do modo de fazer convencional - para o qual se busca uma solução inovadora, capaz de gerar melhoria de desempenho" (Guerra, 2016, p. 3, grifos do autor). O pesquisador também esclarece que:

A pesquisa aplicada "permite a formatação operacional de ideias", o que significa produzir uma sistematização conceitual que possa ser operacionalizada, através de métodos e procedimentos técnicos, na forma de mecanismos de gestão, de processos e de produtos que visem oferecer soluções ao "objetivo ou propósito prático" inicialmente estabelecido (Guerra, 2016, p. 8).

Complementar a isso, Assis (2018, p. 140) entende que a realização da pesquisa aplicada na área "[...] é pertinente quando as situações da vida real demonstram necessidade de ações sobre elas, seja de modo a modificar seus rumos, seja complementando o que já existe ou criando algo novo, em substituição". Para o autor, é através do olhar sobre cenário no qual o jornalismo se desenvolve que se pode reconhecer quando essa aplicabilidade se faz necessária.

De acordo com Guerra (2016), a solução produzida a partir da pesquisa aplicada é de natureza teórico-prática, a qual pode avançar para o desenvolvimento experimental, elaborando novos produtos e processos. Esta seria uma forma de complementar a sistematização conceitual desenvolvida a partir da pesquisa aplicada - uma demanda, no entanto, que decorre do próprio problema de pesquisa (Ibid.).

Santos (2015) corrobora com Guerra, mas considera que a pesquisa aplicada não deve restringir-se à dimensão experimental. Isso porque, na pesquisa experimental, o investigador busca o maior controle possível das variáveis a fim de identificar correlação e/ou causalidade para refutar ou comprovar determinada hipótese. Já na pesquisa aplicada tende-se a observar os efeitos a partir de um contexto mais amplo, "[...] adotando uma abordagem focada na interconexão entre o problema, os objetivos da 
solução, o perfil de seus usuários, seus contextos de uso e certo grau de incerteza, caracterizando uma abordagem orientada à complexidade" (Santos, 2015, p. 20-21).

Assim, embora voltada a um problema prático, a teoria não deve estar dissociada deste tipo de investigação; pelo contrário, é ela que fornece subsídios para a compreensão e abordagem do objeto de estudo (Guerra, 2016; Franciscato, 2006). A pesquisa bibliográfica configura-se como uma etapa inicial e básica da pesquisa aplicada, permitindo fundamentar o tema, conhecer estudos semelhantes e identificar técnicas e procedimentos adequados para a pesquisa em questão (Renó, 2014).

Adiciona-se à pesquisa teórica a importância da pesquisa empírica acerca de iniciativas relacionadas ao objeto de estudo, pois permite conhecer o que já vem sendo feito e o que ainda deve ser qualificado. Os dados oriundos dos processos empíricos são empregados para projetar as soluções buscadas, "[...] onde o pesquisador age de forma mais ativa utilizando o que coletou a fim de construir algo novo ou, pelo menos, que apresente diferenças em relação ao que até então é utilizado, para o enfrentamento do problema real que motivou a atividade de pesquisa" (Santos, 2015, p. 21).

Também, é relevante planejar uma possível testagem da proposta elaborada, inclusive para proposições conceituais. Assim como nos processos inovativos, a testagem é uma etapa relevante, possibilitando refletir a inserção da ideia no tecido social, com opiniões de possíveis utilizadores (Santos, 2015), e permitindo realizar adequações aos contextos em que será inserida.

Além de possibilitar a produção de conhecimento para a aplicação prática no campo jornalístico, a realização de pesquisas aplicadas na universidade tem o potencial de contribuir para a formação dos futuros jornalistas, capacitando-os para atuar em uma indústria que é atravessada por transformações em diferentes esferas. Corroboram com esse entendimento Machado e Teixeira (2016, p. 107), autores que sublinham que o cenário de crise acentua a necessidade em integrar ensino e pesquisa aplicada, onde os graduandos podem se tornar "agentes de mudança" a partir de projetos transdisciplinares com foco no desenvolvimento de novos formatos, linguagens, técnicas, processos e protótipos de plataformas de produção de conteúdo.

Essa também pode ser uma forma de aproximar academia e mercado de trabalho, pois ainda existe um distanciamento entre o conhecimento produzido no ambiente acadêmico e as práticas desenvolvidas pelas empresas de mídia. Uma pesquisa conduzida por Weiss et al. (2020) na América Latina demonstrou, por exemplo, que estudantes e educadores do jornalismo foram mais propensos a discordar que eram inovadores do que os profissionais que atuavam em empresas próprias ou de terceiros, o que, segundo os autores, pode estar relacionado ao fato de que alunos e professores 
são menos ativos na indústria jornalística. Weiss et al. (2020) consideram ainda que talvez as universidades latino-americanas não estejam promovendo a inovação tanto quanto estudantes e docentes gostariam, e que a academia pode estar ficando para trás na promoção de um ambiente inovador.

Após a abordagem da pesquisa aplicada no jornalismo, compreendendo-a como uma perspectiva de inovação no campo, apresentamos a seguir o relato do processo de desenvolvimento metodológico de uma pesquisa de doutorado relacionada ao jornalismo móvel.

\section{Processos metodológicos de uma pesquisa de doutorado aplicada}

O cenário de crise no jornalismo destacado no início deste trabalho, no qual veículos tradicionais de mídia encontram dificuldades para adaptar-se à era digital e às atuais mudanças no campo, fomentou o desenvolvimento de uma pesquisa de doutorado que pudesse lançar luz a algumas questões relacionadas ao tema, especialmente no que se referia ao jornalismo móvel (Alexandre, 2021).

Partindo do pressuposto de que as funcionalidades específicas dos dispositivos móveis podem tornar as narrativas mais completas, interessantes e acessíveis aos usuários, a tese buscou responder o seguinte problema: Considerando o contexto de mobilidade, as especificidades dos dispositivos móveis e o acesso a notícias nestes suportes, como qualificar a produção do jornalismo para smartphones e tablets através de uma linguagem jornalística móvel autóctone?

Com a proposta de desenvolver parâmetros que pudessem auxiliar na produção jornalística, a tese caracterizou-se como uma pesquisa aplicada, combinando diferentes procedimentos metodológicos e técnicas de investigação. À medida que o contato com as teorias, métodos e objeto empírico se aprofundava, percebíamos a necessidade em desenvolver outros processos para nos aproximarmos do objetivo do estudo.

Teoria e método foram pensados de maneira integrada na tese, possibilitando a construção e a experimentação de abordagens específicas para a pesquisa. Essa necessidade de experimentação teórico-metodológica foi ainda mais acentuada devido à especificidade da pesquisa aplicada, tipo de investigação nunca realizado por nós e que também não é comum em cursos de pós-graduação stricto sensu na área, como ressaltado anteriormente.

Em função do viés voltado à prática, percebemos também a importância de uma vigilância epistemológica, ação que se dá, segundo Bourdieu, Chamboredon e Passeron (2010), através da interrogação sobre as técnicas e conceitos utilizados, do abandono à aplicação automática de modelos e procedimentos já utilizados e por meio do exercício 
contínuo de repensar toda e qualquer operação executada. Essa compreensão vai ao encontro do que defende Assis (2018), de que a pesquisa aplicada deve desenvolver-se a partir de um movimento dialético entre vislumbrar possíveis soluções práticas ao mesmo tempo em que se faz crítica, pois,

Caso contrário, a pesquisa aplicada nada mais será do que uma pretensa validação acadêmica de interesses previamente esboçados pelo mercado, incorrendo no erro maior de reforçar práticas jornalísticas perniciosas ou, no mínimo, de fazer crer que a aplicabilidade da pesquisa acadêmica redunda em algo que ela não é (Assis, 2018, p. 146).

Deste modo, tal como sublinha Franciscato (2006), é essencial a uma pesquisa aplicada a construção de um quadro teórico de base, fornecendo os conceitos que embasam a caracterização e a definição dos fenômenos. Com esse suporte teórico, é possível delinear modos de operacionalizar a intervenção do pesquisador na realidade, fundamentando a produção do conhecimento.

Com isso em vista, a pesquisa foi estruturada a partir de três dimensões: teórica, empírica e experimental. A dimensão teórica correspondeu à pesquisa bibliográfica baseada em produções científicas relacionadas às temáticas exploradas no estudo, como jornalismo móvel, inovação e arquitetura da informação. A dimensão empírica contemplou etapas que permitiram compreender o que já era produzido por empresas jornalísticas para o ambiente móvel como também produzir dados relacionados ao modo como as pessoas usam seus smartphones e consomem notícias nos dispositivos móveis. A articulação dessas duas dimensões fundamentou a elaboração conceitual dos parâmetros para uma linguagem nativa para dispositivos móveis, que avançou ainda para uma dimensão experimental, na qual foi desenvolvido um protótipo de produto jornalístico para smartphones com base em algumas diretrizes propostas.

A Figura 1 ilustra a articulação entre as dimensões da pesquisa aplicada que compõem a tese. As setas com sentido duplo têm o objetivo de demonstrar que o processo não foi linear, em que cada dimensão foi construída e revisitada de acordo com o desenvolvimento da investigação. A dimensão experimental necessitou das dimensões teórica e empírica para ser materializada; do mesmo modo, teorias e empírico foram pensados com vistas à elaboração do protótipo, e fazem sentido a partir do processo experimental. 
Figura 1 Dimensões da pesquisa aplicada desenvolvidas na tese.

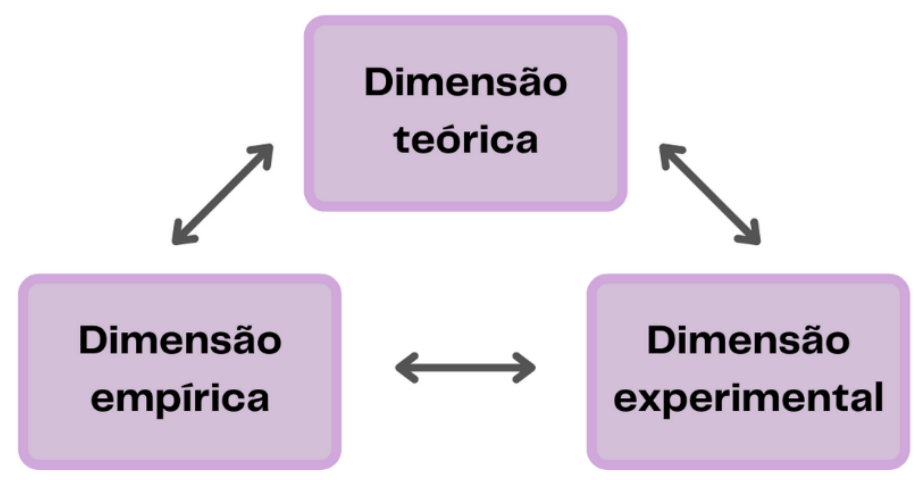

Fonte: Elaborado pelas autoras (2021)

Os procedimentos metodológicos da tese foram delineados a partir de uma adaptação da metodologia projetual do design, que tem como objetivo organizar e delimitar etapas, processos e técnicas necessários à elaboração de um produto. Entre as diversas concepções desta metodologia, baseamo-nos no Projeto E, que se destina ao desenvolvimento de interfaces gráficas amigáveis para sistemas e produtos interativos dígito-virtuais, e constitui-se em seis fases: estratégia, escopo, estrutura, esqueleto, estética e execução (Meurer \& Szabluk, 2010).

A etapa de estratégia integra as definições das questões projetuais, identificação dos cenários, qual a situação em que se pretende chegar, equalização dos fatores do projeto e taxonomia. A fase de escopo trata da organização do conteúdo em categorias e início da definição das funcionalidades e ferramentas. A etapa de estrutura é dedicada ao organograma do produto. A fase seguinte, esqueleto, propõe a organização estrutural do conteúdo. Na etapa de estética é definida a identidade gráfico-visual do projeto. $E_{\text {, }}$ por fim, a fase de execução corresponde à programação do produto, neste caso, a produção do protótipo (Meurer \& Szabluk, 2010).

A Figura 2 representa a linha temporal de construção da tese, com indicação dos processos empíricos e experimentais realizados. Consideramos que a pesquisa teórica foi o fio condutor em todas as etapas, por isso não indicamos um único momento para a sua realização. 
Figura 2 Processos desenvolvidos na tese.

$\begin{array}{cccc}\text { Pesquisa } & \text { Teste de } & \text { Definições } & \\ \text { exploratória } & \text { usabilidade } & \text { público e } & \text { Produção } \\ \text { em apps } & \text { app DW } & \text { tecnologia } & \text { protótipo } \\ \text { (estratégia) } & \text { (estratégia) } & \text { (estratégia) } & \text { (execução) }\end{array}$

(1)

(3)

(5)

(7)

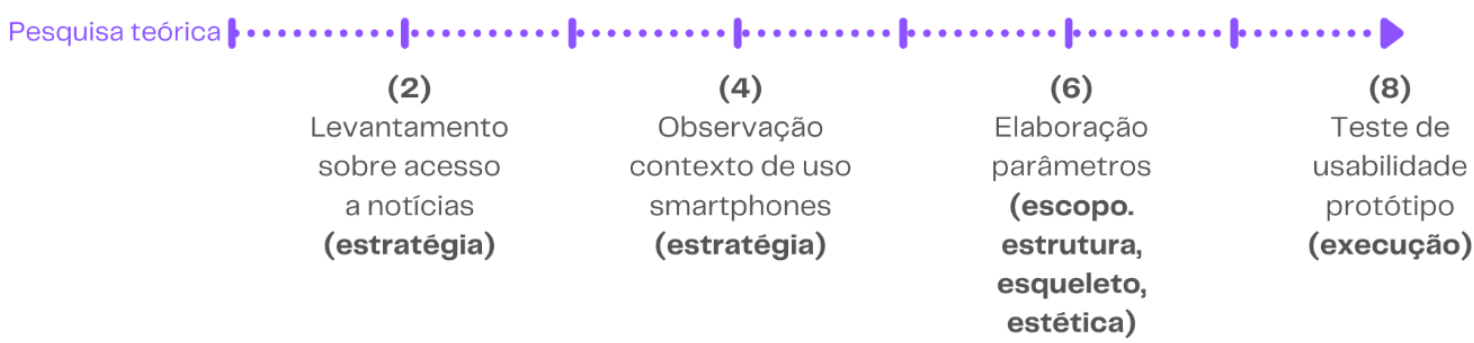

Fonte: Elaborado pelas autoras (2021)

A seguir abordamos a síntese de cada processo metodológico desenvolvido na pesquisa. Como o foco deste estudo é a construção metodológica da investigação, não serão explorados os resultados das etapas. Os detalhes sobre a metodologia e os dados produzidos a partir desses procedimentos podem ser conferidos na tese (Alexandre, 2021).

\section{a) Pesquisa exploratória em apps jornalísticos}

A fim de elaborar o processo de identificação dos cenários, relacionado à etapa de estratégia, foi realizado um exercício exploratório de observação de aplicativos (apps) jornalísticos para dispositivos móveis. Devido ao grande número de aplicações encontradas, optamos por desenvolver esta atividade em duas fases. A primeira correspondeu à descrição geral de 219 apps jornalísticos brasileiros e internacionais, observando aspectos referentes a sete características do webjornalismo: multimidialidade, ubiquidade, hipertextualidade, instantaneidade, memória, interatividade e personalização (Canavilhas, 2014). A segunda fase caracterizou-se pela descrição aprofundada de dois aplicativos, DW e Quartzı a partir de seis categorias (interface, interatividade e imersão, conteúdo, personalização, distribuição e contexto).

Essas explorações ocorreram em diferentes períodos do desenvolvimento da pesquisa, entre 2017 e 2020, e permitiram compreender o que já vinha sendo feito na área, o funcionamento dessas produções, bem como levantar características que pudessem ser agregadas aos parâmetros propostos. 


\section{b) Levantamento sobre acesso a notícias}

Com o objetivo de compreender questões sobre o consumo de notícias em dispositivos móveis, contribuindo para a delimitação do público, realizamos em 2017 um levantamento por meio de um questionário on-line com 432 estudantes de ensino de graduação e pós-graduação brasileiros. Segundo Prodanov e Freitas (2013), um levantamento é um tipo de pesquisa útil para o estudo do comportamento de um determinado público. Apesar do viés quantitativo, esse processo foi empregado para explorar e conhecer mais sobre a questão, gerando dados que pudessem embasar outras etapas da tese.

\section{c) Teste de usabilidade no aplicativo DW}

Outro processo relacionado à etapa de estratégia correspondeu a um teste de usabilidade no aplicativo $D W$, da empresa Deutsche Welle. O teste de usabilidade é uma ferramenta metodológica que permite avaliar a maneira como os usuários acessam e interagem com uma interface, verificando quais são os atributos que tornam a navegação mais eficiente e proveitosa ao público (Nielsen \& Loranger, 2007). A experiência foi realizada em 2018 com nove estudantes de pós-graduação em Comunicação do Rio Grande do Sul, a partir de uma adaptação do método STBI (Entrevistas Baseadas em Cenários e Tarefas) (Agner, Gomes \& Muniz, 2014), e permitiu identificar aspectos relativos à eficácia e satisfação de navegação no app, como recursos mais usados e dificuldades/facilidades de interação com o produto.

\section{d) Observação do contexto de uso de smartphones}

A fim de complementar os dados obtidos no levantamento on-line com estudantes brasileiros, elaboramos em 2019 uma observação do contexto de uso e acesso a notícias em smartphones por oito pós-graduandos em Comunicação residentes na Espanha. Para essa etapa, foram realizadas a coleta de dados do gasto de bateria/dados móveis dos aparelhos dos participantes ao longo de cinco semanas e entrevistas semiestruturadas individuais. Os dados dos aparelhos continham o tempo e/ou porcentagem de uso de bateria dos aplicativos instalados, indicando os mais utilizados. As entrevistas individuais, por sua vez, versaram sobre hábitos de uso e o consumo de conteúdos jornalísticos nos telefones móveis. Essa etapa contribuiu para ampliar a compreensão sobre como os jovens utilizam seus dispositivos e buscam, acessam e interagem com notícias. 


\section{e) Definição de público e tecnologia}

A partir da pesquisa teórica e dos processos empíricos realizados, definimos que a proposta de parâmetros e o protótipo seriam pensados visando jovens estudantes de ensino superior e smartphones. A escolha por esse grupo foi fundamentada em pesquisas que revelam uma estreita relação entre eles e os dispositivos móveis. São os jovens que mais navegam na internet e utilizam os devices e os que mais consomem notícias nesses aparelhos (IBGE, 2020). Outro motivo que contribui para essa opção corresponde à importância em se investigar com maior atenção as gerações mais novas, especialmente diante do cenário de queda de audiências e envelhecimento do público dos meios tradicionais. Já o recorte por estudantes universitários diz respeito ao fato de que uma grande parcela dos alunos de ensino superior no Brasil está nas faixas etárias mais novas da população (INEP, 2019). Também, por estarmos inseridas no ambiente universitário, o que facilitava a aproximação com esse público e a realização da pesquisa.

A escolha por construir o protótipo para smartphones foi necessária em função do tempo e recursos disponíveis para a produção do objeto. Entendemos que existem diferenças entre as características dos dispositivos móveis, bem como no modo como as notícias são acessadas em cada tipo de aparelho. O smartphone foi selecionado por ser mais utilizado do que o tablet no país (FGV, 2020). Também, por concentrar o maior acesso à internet móvel no Brasil (CETIC.BR, 2020) e devido ao registro de aumento no consumo de notícias nesses aparelhos nos últimos anos (Newman et al., 2020).

\section{f) Elaboração dos parâmetros de linguagem jornalística móvel}

Os processos desenvolvidos até essa fase da pesquisa possibilitaram a produção de conhecimento acerca objeto de estudo, reunindo referências para a proposição de parâmetros para a linguagem jornalística autóctone para dispositivos móveis. A proposta conceitual foi organizada em cinco macrocategorias (público, conteúdo, narrativa, interface e estrutura), e 31 elementos (ou subcategorias), selecionados a partir das pesquisas teórica e empírica realizadas. $\mathrm{O}$ arranjo construído serviu como um guia para a produção do protótipo, mas avaliamos que pode ser adaptado para outras investigações e produções com propósitos e públicos diferentes, tendo em vista que contempla os principais aspectos que devem ser planejados em um produto jornalístico para dispositivos móveis. Na tese é possível verificar o detalhamento da proposta.

\section{g) Produção do protótipo de produto jornalístico móvel}

O desenvolvimento do protótipo teve como objetivo materializar e testar alguns parâmetros propostos. Em função do tempo e dos recursos disponíveis, o objeto 
correspondeu a uma amostra das telas de uma produção jornalística para smartphones voltada ao público jovem, apresentando alta fidelidade em aparência, mas com algumas restrições nas suas funcionalidades e interações.

O protótipo foi construído em 2020 através da plataforma Figma ${ }^{6}$, que permite elaborar a interface e prototipar interações simples entre elementos, e contou com o auxílio de um profissional da área de User Experience para o refinamento do design. $O$ objeto foi abastecido com conteúdos e componentes da identidade visual da Beta Redação ${ }^{7}$, projeto experimental do curso de Jornalismo da Universidade do Vale do Rio dos Sinos (Unisinos). A parceria foi realizada visando agilizar o processo de produção, além de estabelecer uma ponte com o ensino da profissão e valorizar as práticas experimentais da graduação. As matérias foram adaptadas para atender as especificidades da proposta. Ao todo, foram desenhadas 20 páginas diferentes, incluindo tela inicial, menu, editorias e notícias, como demonstra a Figura 3.

Figura 3 Visão geral das telas do protótipo.

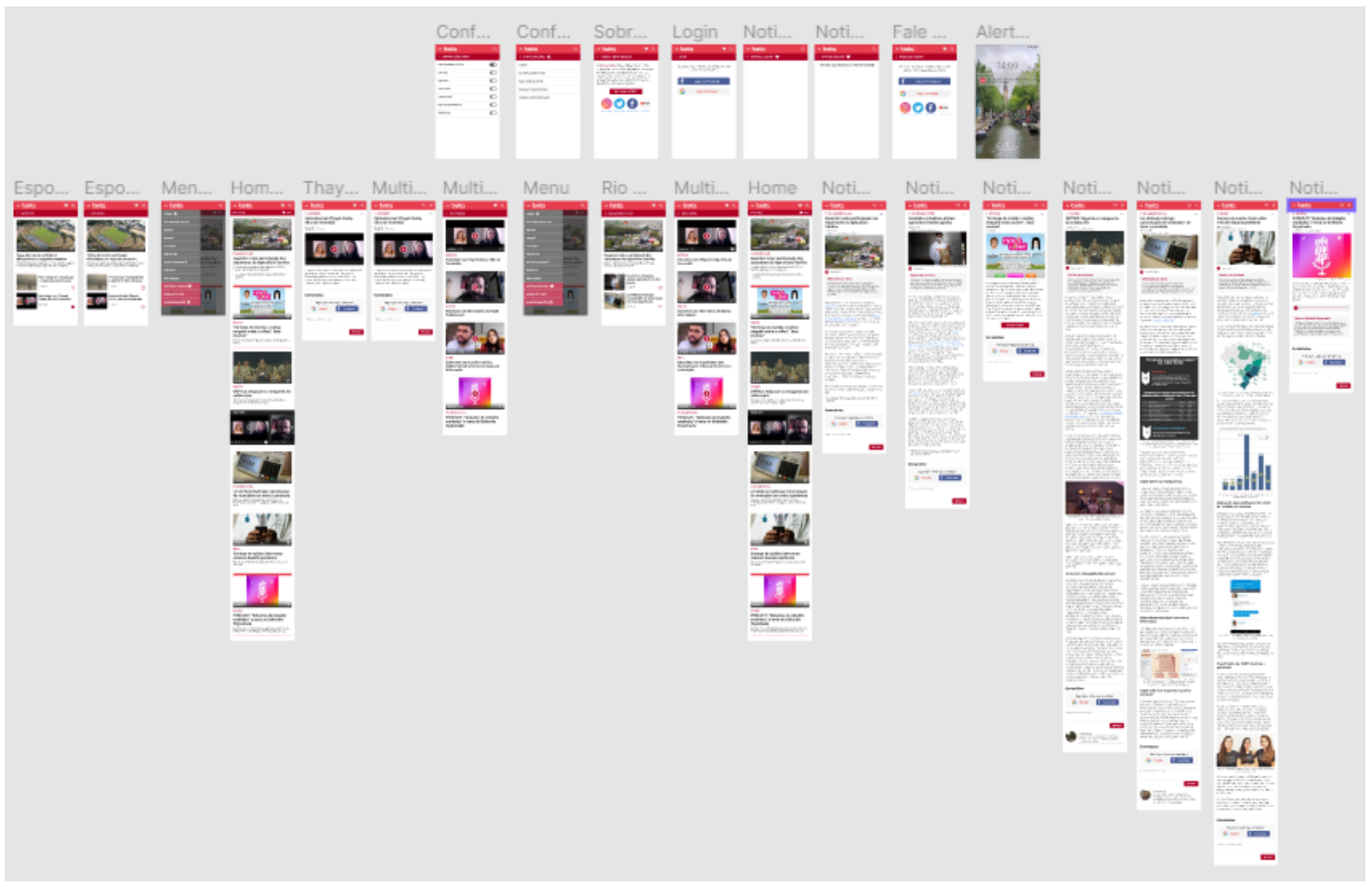

Fonte: Elaborado pelas autoras (2020)

\footnotetext{
${ }^{6}$ Disponível em: https://www.figma.com/.

${ }^{7}$ Disponível em: https://medium.com/betaredacao.
} 


\section{h) Teste de usabilidade no protótipo}

Após a elaboração do protótipo, foi realizado em 2020 um teste de usabilidade no objeto com 16 estudantes de ensino superior residentes no Rio Grande do Sul, seguindo também uma adaptação do método STBI (Agner, Gomes \& Muniz, 2014). Devido à pandemia de Covid-19, a avaliação foi realizada de maneira remota, por meio de videochamadas individuais, em que cada estudante compartilhava a tela do seu smartphone e tecia comentários enquanto realizava as tarefas propostas pelas pesquisadoras. O objetivo da avaliação foi o de avaliar a facilidade de acesso e a satisfação de navegação, com foco na localização de informações e no uso de recursos do objeto. A experiência possibilitou compreender melhor a aplicação prática dos parâmetros de linguagem jornalística móvel e identificar a percepção dos participantes sobre algumas diretrizes propostas.

\section{Reflexões sobre o processo da pesquisa aplicada}

O desenvolvimento da tese permite tecer algumas reflexões relacionadas à realização de pesquisas aplicadas na academia. Inicialmente, destacamos o quanto a construção teórico-metodológica como um todo foi fundamental para a elaboração dos parâmetros e produção do protótipo. A intenção em chegar a um resultado que pudesse ser testado existia desde o projeto da pesquisa, mas no início do doutorado ainda não sabíamos se avançaríamos para essa fase. Foi, então, a partir da experimentação de teorias, métodos e técnicas durante a trajetória de investigação que se tornou possível reunir os subsídios para realizar a proposição.

Em referência à etapa experimental, avaliamos que a construção do protótipo foi proveitosa à pesquisa, possibilitando complementar os achados teóricos e empíricos, testar com usuários alguns dos parâmetros e entender melhor como se dá o processo da produção jornalística para smartphones. Ainda, a prototipação e a testagem revelaram que é essencial compreender os usos que o público fará do produto.

Referente aos processos inovativos e à pesquisa aplicada, o desenvolvimento da tese revela alguns aspectos relevantes para a compreensão de como esse tipo de projeto pode ser pensado no ambiente acadêmico. Um primeiro ponto diz respeito às vantagens que a universidade proporciona à condução de processos inovativos, incluindo a questão do tempo. Tivemos quase quatro anos para investigar e propor os parâmetros de linguagem jornalística para dispositivos móveis, um período que raramente as empresas disponibilizam para suas equipes. A academia permite um nível de aprofundamento e amadurecimento maior do projeto antes que a ideia seja inserida no tecido social. É claro que os resultados de uma inovação são imprevisíveis, tanto aquelas projetadas pelas 
instituições de ensino quanto pelas organizações empresariais, pois dependem dos usos e apropriações feitas pela sociedade. Porém, talvez a falta de tempo de pesquisa e planejamento estejam entre os motivos que explicam a descontinuidade de experiências lançadas pela indústria midiática, como de alguns aplicativos móveis jornalísticos e revistas para tablets. Em um cenário ideal, universidades e veículos de comunicação trabalhariam juntos para pensar soluções para os problemas enfrentados pelo campo, tal como já fazem alguns media labs.

Outro benefício das universidades é reunir, em um mesmo espaço, investigadores e profissionais de diferentes áreas, uma vez que a interação multidisciplinar se faz necessária para estes projetos, como demonstrou a elaboração da pesquisa. Sem as referências de outros campos do conhecimento, conversas com colegas de cursos diferentes e o auxílio do profissional de User Experience, teria sido mais difícil, demorado e custoso propor os parâmetros e construir o protótipo.

A investigação indicou também o potencial que a pesquisa aplicada tem para integrar graduação e pós-graduação. Na tese, a parceria ocorreu por meio da inclusão dos conteúdos produzidos pela Beta Redação no protótipo, o que foi essencial para agilizar a sua elaboração, mas em outros estudos a participação pode se dar de outras maneiras, como buscar soluções para problemas relacionados à formação profissional e envolver os estudantes em todas as etapas de idealização e construção do projeto, por exemplo. Compreendemos que a colaboração favorece os dois lados, aliando teoria e prática, reduzindo o distanciamento entre a graduação e os cursos de mestrado e doutorado e possibilitando qualificar o ensino de jornalismo, como já sublinhavam Machado e Teixeira (2016).

Apesar das oportunidades, percebemos que desenvolver uma pesquisa aplicada não é tão simples - o que também pode explicar por que essa perspectiva de investigação não é tão recorrente na comunicação e jornalismo, embora sejamos uma Ciência Social Aplicada. Em algumas situações notamos o desconhecimento e/ou afastamento deste tipo de estudo nos programas de mestrado e doutorado acadêmicos, dificultando a formação de um debate sobre o papel da pesquisa aplicada na produção científica no campo. Em função da nossa própria falta de experiência, tivemos dificuldades em entender quais teorias e métodos poderiam auxiliar na investigação do problema - o que acabou impulsionando também a experimentação teóricometodológica destacada acima.

As restrições de equipe e orçamento são mais um fator que podem impedir a pesquisa aplicada de avançar para uma etapa experimental. No caso da tese, a construção do protótipo não teve custo financeiro, entretanto, avaliando as opções que 
existem para a produção de sites e aplicativos móveis, conseguiríamos testar mais elementos se dispuséssemos de valores para financiar programas e/ou a participação de mais pesquisadores e profissionais no projeto.

Apesar do cenário desafiador, a investigação de doutorado demonstrou que a pesquisa aplicada é um caminho possível para se refletir criticamente o jornalismo e planejar soluções que possam contribuir para as práticas jornalísticas, especialmente neste contexto de crise pelo qual atravessamos. Isto posto, na próxima seção abordamos as considerações finais do estudo, com apontamentos mais gerais sobre o tema.

\section{Considerações}

O presente estudo buscou debater a pesquisa aplicada como uma perspectiva de inovação metodológica no jornalismo por meio do relato do processo de construção de uma investigação de doutorado. Apesar de estar relacionada a uma tese específica, acreditamos que o trabalho pode contribuir para outros estudos em jornalismo e comunicação que visam trabalhar a partir da pesquisa aplicada.

No contexto de crise no jornalismo, acreditamos que as pesquisas científicas têm um importante papel para ajudar a refletir sobre o cenário e debater possíveis caminhos frente às intensas mudanças que afetam o campo. Diante da complexidade dos fenômenos, entendemos que recorrer a metodologias e técnicas usualmente empregadas nas investigações pode não fornecer os subsídios suficientes para a compreensão dos problemas investigados, surgindo, aí, a possibilidade de se inovar metodologicamente. Tal como salienta Franciscato (2017, p. 43), "[...] uma eventual execução de procedimentos metodológicos inovativos poderia oferecer maiores condições para formulação de novos modos de pensar o jornalismo, assim como a proposição de novos conceitos e abordagens metodológicas do objeto".

Nessa direção, consideramos que a pesquisa aplicada pode ser um caminho produtivo para buscar soluções e desenvolver projetos inovadores no jornalismo. $O$ processo de desenvolvimento da tese relatado realça desafios na realização deste tipo de investigação, tanto em função de limitações de recursos como pela própria natureza dessa perspectiva de pesquisa. No entanto, ressaltamos as possibilidades de experimentação teórico-metodológica que se abrem a partir da pesquisa aplicada, em se testar outras abordagens - possibilitando, assim, promover a inovação metodológica (Franciscato, 2017).

Com o relato, procuramos também demonstrar a articulação e a interação entre o que denominamos como "dimensões da pesquisa aplicada", os processos teórico, empírico e experimental. Por voltar-se à prática, a pesquisa aplicada pode ter sua 
cientificidade questionada - um receio de que apenas sejam buscadas soluções para os problemas identificados no fazer jornalístico sem que haja uma reflexão crítica a respeito. No entanto, ressaltamos o quanto a fundamentação e problematização teórica são essenciais neste tipo de investigação, pois, como ressaltam Franciscato (2006), Guerra (2016) e Renó (2014), é a partir da teoria que podemos tensionar o objeto e embasar as proposições. Do mesmo modo, é justamente o processo reflexivo sobre esse fazer que irá diferenciar a pesquisa aplicada da simples validação do que é feito no mercado (Assis, 2018).

As referências consultadas e o processo de construção da tese permitem compreender ainda que a etapa experimental se configura como uma via para a produção e aplicação do conhecimento, tal como propõe Guerra (2016). Porém, desta perspectiva de investigação podem surgir também proposições conceituais para consulta e/ou aplicação de outros estudantes, pesquisadores e profissionais.

O levantamento sobre a pesquisa aplicada em dissertações e teses sobre comunicação móvel, mencionado neste trabalho, evidencia também o seu potencial para abordar diferentes questões relacionadas a uma mesma área do jornalismo. No entanto, este mapeamento, em conjunto com estudos como os realizados por Franciscato (2017), Machado e Rohden (2016) e Lopez e Maritan (2015), evidencia que a pesquisa aplicada ainda não é uma perspectiva recorrente nas investigações em jornalismo. Acreditamos que o desconhecimento e/ou afastamento deste tipo de pesquisa em programas de mestrado e doutorados acadêmicos e a ausência de um planejamento metodológico que vise a projeção dos resultados estão entre os fatores que contribuem para esse cenário.

Outro ponto que pode inviabilizar esse tipo de aplicação da ciência é a carência de recursos para o desenvolvimento de soluções a partir dos conhecimentos gerados através da pesquisa teórica e empírica. Em muitos casos, há a necessidade de profissionais capacitados e do envolvimento de outras áreas do conhecimento para trabalhar nos projetos, o que pode inibir a proposição de pesquisas de formato aplicado. A própria tese de doutorado relatada neste trabalho exemplifica essas limitações.

Destacamos o potencial de a universidade ser o espaço para o desenvolvimento de pesquisas aplicadas, adotando uma postura proativa em relação ao mercado e propondo soluções para problemas que afetam a sociedade. Em tese, a academia não está atrelada ao ritmo e às lógicas mercadológicas, o que permite dedicar tempo para o aprofundamento teórico-metodológico. Também, reúne especialistas de distintas áreas, os quais podem trabalhar coletivamente a partir das abordagens e dos interesses de cada ciência. 
Por fim, acreditamos que o conhecimento relativo à pesquisa aplicada precisa ser partilhado para que mais pesquisadores possam interessar-se por essa modalidade investigativa. Uma iniciativa neste sentido consiste no Prêmio Adelmo Genro Filho, da Associação Brasileira de Pesquisadores em Jornalismo (SBPJor), que desde 2018 conta com uma categoria voltada a produtos e projetos caracterizados como de aplicação prática. Outra possibilidade refere-se ao debate sobre o tema em congressos e em cursos de graduação e pós-graduação, familiarizando os pesquisadores com a pesquisa aplicada e, possivelmente, aumentando a sua aceitação.

\section{Referências}

Agner, L., Gomes, L. A. De M. \& Muniz, M. I. (2014). Jornalismo para tablets: interações gestuais em um aplicativo de notícias. Ação ergonômica, 9(1). Recuperado de: https://www.revistaacaoergonomica.org/revista/index.php/ojs/article/view/201/2 00.

Aguado, J. M., Feijóo, C. \& Martínez, I. J. (2015). A mobile revolution inside a digital Revolution. (J. M. Aguado, C. Feijóo, I. J. Martínez, Orgs.). Emerging Perspectives on the Mobile Content Evolution. Hershey, PA: IGI Global. DOI: 10.4018/978-14666-8838-4.

Alexandre, T. B. (2021). Linguagem jornalística autóctone para dispositivos móveis. (Tese de doutorado). Programa de Pós-graduação em Ciências da Comunicação, Universidade do Vale do Rio dos Sinos, São Leopoldo, RS, Brasil.

Anderson, C. W., Bell, E. \& Shirky, C. (2013) Jornalismo pós-industrial: adaptação aos novos tempos. Revista de Jornalismo ESPM, 2(5), 30-89.

Assis, F. De. (2018). Pesquisa aplicada em jornalismo: o desafio da construção do objeto. Comunicação \& Inovação, 19(41), 133-148. Recuperado de: https://seer.uscs.edu.br/index.php/revista_comunicacao_inovacao/article/view/55 18.

Barbosa, S., Silva, F. F. Da, Nogueira, L. \& Almeirda, Y. (2013). A atuação jornalística em plataformas móveis: Estudo sobre produtos autóctones e a mudança no estatuto do jornalista. Brazilian Journalism Research, 9(2), 10-29. Recuperado de: https://bjr.sbpjor.org.br/bjr/article/view/549.

Bourdieu, P., Chamboredon, J. \& Passeron, J. (2010). Ofício de sociólogo: metodologia da pesquisa na sociologia. 7. ed. Petrópolis: Vozes.

Cabrera González, M. A. (2016). La innovación: concepto y taxomización. In: Sábada Chalezquer, C., García-Avilés, J. A. \& Martínez Costa, M. D. P. (Orgs.). Innovación y desarrollo de los cibermedios en España. Madri: EUNSA.

Canavilhas, J. (Org.) (2014). Webjornalismo. 7 características que marcam a diferença. Covilhã: LabCom Books.

Carlón, M. (2016). Después del fin: una perspectiva no antropocéntrica sobre la post-tv, el post-cine y youtube. Buenos Aires: La Crujía.

Cetic.Br. (2020). TIC Domicílios e Usuários 2019. Recuperado de: https://www.cetic.br/media/analises/tic_domicilios_2019_coletiva_imprensa.pdf. 
Charron, J. \& Bonville, J. de. (2016). Natureza e transformação do jornalismo. Florianópolis: Insular; Brasília: FAC Livros.

Deuze, M. \& Witschge, T. (2016). O que o Jornalismo está se tornando. Parágrafo, 4(2). Recuperado de: http://revistaseletronicas.fiamfaam.br/index.php/recicofi/article/view/478/445.

Dogruel, L. (2017). O que há de tão especial nas inovações midiáticas?: uma caracterização do campo. Contemporanea, 15(01), 25-46. Recuperado de: https://periodicos.ufba.br/index.php/contemporaneaposcom/article/view/22167.

FGV. (2020). 31 a Pesquisa Anual do Uso de TI. Recuperado de: https://eaesp.fgv.br/producao-intelectual/pesquisa-anual-uso-ti.

Flamingo. Reuters Institute. (2019). How Young People Consume News. and The Implications For Mainstream Media. Recuperado de:

https://reutersinstitute.politics.ox.ac.uk/our-research/how-young-peopleconsume-news-and-implications-mainstream-media.

Franciscato, C. E. (2017). A inovação metodológica como problema na pesquisa em jornalismo digital. Contemporanea, 15(01), 25-46. Recuperado de: https://periodicos.ufba.br/index.php/contemporaneaposcom/article/view/21513.

Franciscato, C. E. (2010). Uma proposta de incorporação dos estudos sobre inovação nas pesquisas em jornalismo. Estudos em Jornalismo e Mídia, 7(01). Recuperado de: https://periodicos.ufsc.br/index.php/jornalismo/article/view/19846924.2010v7n1p8.

Franciscato, C. E. (2006). Considerações metodológicas sobre a pesquisa aplicada em jornalismo. In Anais do $4^{\circ}$ Encontro Nacional da Associação Brasileira de Pesquisadores em Jornalismo, 2006, Porto Alegre, RS, Brasil.

Guerra, J. L. (2016). Qualijor - Sistema de Gestão da Produção Jornalística orientado para a qualidade editorial: Pesquisa Aplicada e de Desenvolvimento Experimental em Jornalismo. E-compós, 19(3). Recuperado de: https://www.e-compos.org.br/ecompos/article/view/1291.

Henn, R. \& Oliveira, F. M. De. (2015). Jornalismo e movimentos em rede: a emergência de uma crise sistêmica. Revista Famecos, 22(3). Recuperado de: https://revistaseletronicas.pucrs.br/ojs/index.php/revistafamecos/article/view/205 60.

IBGE. (2020). Pesquisa Nacional por Amostra de Domicílios Contínua 2018. Recuperado de: https://biblioteca.ibge.gov.br/visualizacao/livros/liv101705_informativo.pdf.

INEP. (2019). Censo da Educação Superior 2018. Recuperado de: http://portal.inep.gov.br/web/guest/sinopses-estatisticas-da-educacao-superior.

López-García, X. et al. (2019). Periodismo móvil: Revisión sistemática de la producción científica. Comunicar, 59(27), 9-18. Recuperado de: https://www.revistacomunicar.com/index.php?contenido=detalles\&numero $=59 \&$ articulo=59-2019-01.

Lopez, D. C. \& Maritan, M. (2015). A evolução do método: memória das pesquisas experimental e aplicada nos estudos brasileiros de jornalismo. In Anais do $10^{\circ}$ Encontro Nacional de História da Mídia, Porto Alegre, RS, Brasil.

Machado, E. \& Rohden, J. (2016). Metodologias de pesquisa aplicadas ao jornalismo: Um estudo dos trabalhos apresentados na SBPJor (2003-2007). Brazilian Journalism Research, 12(1), 228-245. Recuperado de: https://bjr.sbpjor.org.br/bjr/article/view/828. 
Machado, E. \& Teixeira, T. (2016). Innovation as an essential part of journalism education in contemporary societies. Journal of Applied Journalism \& Media Studies, 5(1), 103-116. Recuperado de: https://www.ingentaconnect.com/content/intellect/ajms/2016/00000005/000000 01/art00008? crawler $=$ true.

Meurer, H. \& Szabluk, D. (2010). Projeto E: aspectos metodológicos para o desenvolvimento de projetos dígito-virtuais. Ação ergonômica, 5(2).

Newman, N. et al. Reuters Institute. (2020). Digital News Report 2020. Oxford: Reuters Institute; University of Oxford. Recuperado de: http://www.digitalnewsreport.org/.

Nielsen, J. \& Loranger, H. (2007). Usabilidade na web. Projetando websites com qualidade. Rio de Janeiro: Elsevier.

Pew Research Center. (2018). 5 facts about the state of the news media in 2017. Recuperado de: http://www.pewresearch.org/fact-tank/2018/08/21/5-factsabout-the-state-of-the-news-media-in-2017/.

Prodanov, C. C. \& Freitas, E. C. de. (2013). Metodologia do trabalho científico: Métodos e técnicas da pesquisa e do trabalho acadêmico. 2. ed. Novo Hamburgo: Editora Feevale.

Renó, D. (2014). Pesquisa aplicada em comunicação: uma tendência necessária. Comunicação \& Sociedade, 36(1), 7-30. Recuperado de: https://repositorio.unesp.br/handle/11449/135421.

Santos, M. C. dos. (2015). Jornalismo, mobilidade e realidade aumentada: notas sobre possibilidades de utilização. In: Canavilhas, J. \& Satuf, I. (Orgs.). Jornalismo para Dispositivos móveis: produção, distribuição e consumo. Covilhã: Livros Labcom.

Silva, F. F. da. (2015). Jornalismo Móvel. Salvador: EDUFBA.

Singer, J. B. (2014). Sem medo do futuro: ética do jornalismo, inovação e um apelo à flexibilidade. Comunicação e Sociedade, 25, 49-66.

Storsul, T. \& Krumsvik, A. H. (2013). What is Media Innovation? In: Storsul, T. \& Krumsvik, A. H. (Eds.). Media Innovations. A Multidisciplinary Study of Change. Gotemburgo: Nordicom.

Thorson, E. et al. (2015). News use of mobile media: A contingency model. Mobile Media \& Communication, 3(2), 1-19. Recuperado de: https://journals.sagepub.com/doi/10.1177/2050157914557692.

Weiss, A. S. et al. (2020). Defining Journalism Innovation in Latin America: Exploration into perceptions among educators, students, and journalists. Journalism \& Mass Communication Educator, 75(4), 419-435. Recuperado de: https://journals.sagepub.com/doi/abs/10.1177/1077695820935327?journalCode= jmcb.

\section{ABSTRACT:}

This paper discusses applied research as a perspective of methodological innovation in journalism by reporting the process of building a doctoral research about mobile journalism. For this, we relate innovation and crisis in journalism and address aspects related to applied research in the field. We also highlight the methodological processes developed in the thesis, reflecting on the articulation of what we call the theoretical, empirical and experimental dimensions of applied research. We approach the theoretical-methodological experimentation 


\section{Orevisto Observatório}

in this type of investigation, the role of the academy for conducting applied research and the limitations and potential of this research perspective for journalism.

$\begin{array}{lrr}\text { KEYWORDS: } & \text { Applied } & \text { research; } \\ \text { Methodological } & \text { processes; } & \text { Mobile } \\ \text { journalism; Innovation. } & \end{array}$

\section{RESUMEN:}

Este artículo tiene como objetivo discutir la investigación aplicada como una perspectiva de innovación metodológica en el periodismo a través del proceso de construcción de una investigación doctoral sobre periodismo móvil. Relacionamos innovación y crisis en el periodismo y abordamos aspectos relacionados con la investigación aplicada en el campo. Destacamos también los procesos metodológicos desarrollados en la tesis, reflexionando sobre la articulación de lo que llamamos las dimensiones teórica, empírica y experimental de la investigación aplicada. Abordamos la experimentación teóricometodológica en este tipo de investigación, el papel de la academia para la realización de la investigación aplicada y las limitaciones y potencialidades de esta perspectiva de investigación para el periodismo.

PALABRAS CLAVE: Investigación aplicada; Procesos metodológicos; Periodismo móvil; Innovación. 